\title{
Effect of acute maternal ethanol exposure upon fetal development in the rat
}

\author{
HERMAN H. SAMSON, DARCY L. WATERMAN, and S. C. WOODS \\ University of Washington, Seattle, Washington 98195
}

\begin{abstract}
Two studies on the effect of acute ethanol administration during Days 9-12 of gestation showed significant fetal weight reduction (6\%-8\%) in rats from ethanol-treated dams compared to water controls. Maternal weight gains could not account for the differences. These effects of acute doses (3.4 $\mathrm{g}$ ethanol $/ \mathrm{kg}$ body weight), given only during organogenesis, suggest that chronic ethanol exposure during gestation is not required for some developmental retardation to occur. What effect this retardation may have upon subsequent behavioral development remains to be determined.
\end{abstract}

It is well documented that excessive human ethanol intake during pregnancy increases the risks of fetal retardation and malformation. The specific set of morphological abnormalities resultant from maternal ethanol abuse has been called the fetal alcohol syndrome (FAS) (Hanson, Jones, \& Smith, 1976; Jones \& Smith, 1973; Jones, Smith, \& Hanson, 1976; Jones, Smith, Ulleland, \& Streissguth, 1973; Mulvihill \& Yeager, 1976).

Studies of the effects of chronic ethanol administration during gestation in animals partially support the human data (Abel, 1978; Chernoff, 1977; Henderson \& Schenker, 1977; Randall, 1977). These studies indicate that, under some circumstances, chronic ethanol exposure during either the time of organogenesis or the total gestational period can result in fetal malformation and/or embryonic death. Direct correlation has been noted by some investigators (Chernoff, 1977; Randall, 1977) between fetal effects and dose of ethanol. However, the effects of relative moderate, acute doses of ethanol (i.e., a "social drinking"' encounter), occurring particularly during organogenesis, on fetal development have not been thoroughly explored.

Abel (1978) examined the effects of intragastric doses in rats of 1 or $2 \mathrm{~g} / \mathrm{kg}$ ethanol administered throughout gestation. The only observed effect was a decrease in litter size, which also occurred in pairfed controls. Thus, a chronically low level of intragastric ethanol appears to have no effect upon fetal development other than that due to nutritional growth retardation.

Skosyreva (1973) also administered ethanol intragastrically $(5 \mathrm{ml}$ of $40 \%$ ethanol $/ \mathrm{kg}$; this

The authors wish to thank Dr. T. H. Shepard and J. C. Greenaway, Laboratory for Human Embryology, University of Washington, for their assistance. Supported by funds from the Alcohol and Drug Abuse Institute, University of Washington. is approximately $1.6 \mathrm{~g} / \mathrm{kg}$ ) on Days 8 through 14 of gestation in rats. On Day 21 , autopsy revealed that ethanol-treated animals weighed less and had a higher mortality rate than controls. However, no data were given for maternal weight gain or blood ethanol levels, confounding the effects of ethanol with other possibly relevant variables. No malformations were reported. Any effect higher acute doses, given during organogenesis, might have upon fetal development of the rat remains to be determined.

\section{EXPERIMENT 1}

\section{Method}

\section{Animals}

Eighteen adult female rats (Long-Evans strain, inbred by the Department of Psychology, University of Washington, animal facility), weighing between 220 and $265 \mathrm{~g}$ were maintained on ad-lib food (Purina Lab Chow) and water. They were individually housed in standard rodent cages in a temperature and humidity-controlled animal colony room. The artificial light cycled on at $0600 \mathrm{~h}$ and off at $1800 \mathrm{~h}$ each day.

Six sexually experienced adult males (Long-Evans strain) were individually housed and maintained under identical conditions as the females.

\section{Procedure}

Following a short adaptation period (5 days), the females were randomly assigned to one of four experimental conditions: water control group $(\mathrm{N}=6), 2 \mathrm{~g}$ ethanol $/ \mathrm{kg}$ body weight $(\mathrm{N}=4)$, $3 \mathrm{~g}$ ethanol/ $\mathrm{kg}$ body weight $(\mathrm{N}=4)$, and $4 \mathrm{~g}$ ethanol $/ \mathrm{kg}(\mathrm{N}=4)$. The water group was partitioned into three subgroups of two animals each. Each subgroup received a water dosage equal in volume to one of the three doses of ethanol (i.e., 2, 3, or $4 \mathrm{~g} / \mathrm{kg})$. Ethanol solution was made daily $(15 \% \mathrm{v} / \mathrm{v}$ solution from $95 \%$ ethanol and tap water).

At $1500 \mathrm{~h}$ on the day following adaptation, the first six females were placed individually into the males' cages. These cages had raised metal floors with paper underneath, which allowed for the presence of vaginal plugs to be checked daily. At $1500 \mathrm{~h}$ the following day, plugs were checked for and those females for which plugs were found were returned to their home cages. If no plugs were found, the females were left with the males for another 24-h period. A new female was introduced into those males' cages in which a plug had been found. This routine was followed 
until all the females were impregnated or if, after 10 days with a male, a female failed to mate successfully (i.e., no presence of vaginal plugs).

On the day of detection of plugs, the females were weighed at $1530 \mathrm{~h}$, and that day was designated Day 0 of gestation. Pregnant animals were weighed on Days $0,3,6,9,10,11,12$, 15,18 , and 20 of gestation. All weighings were made at $1530 \mathrm{~h}$.

On Days 9 through 12, after weighing, each animal received the appropriate drug dosage by intragastric intubation.

On Day 20 of gestation, at $0900 \mathrm{~h}$, the females were weighed and sacrificed by cervical dislocation. The uterus, fetuses, and ovaries were then removed.

\section{Autopsy Procedures}

Immediately upon removal of the uterus, the fetuses were excised from the uterine horns and their positions in the uterus recorded. The yolk sac and other fetal membranes were removed and the umbilical cord cut within $1 \mathrm{~mm}$ of the fetus. Following removal, the viability of the fetus was checked. (This consisted of independent fetal movement to light touch with a forceps.) The placenta was freed from the umbilical cord and membranes by cutting as close as possible to their points of placental attachment. The fetuses were weighed $( \pm .01 \mathrm{~g})$, sexed, and measured (crown to rump length, $\pm .5 \mathrm{~mm}$ ). The placentas were weighed $( \pm .01 \mathrm{~g})$. Each fetus was examined under a dissecting scope $(\times .7)$ for determination of any gross malformations. The uterus was examined for resorptions. The ovaries were examined and the number of corpus lutea noted. One-half of the fetuses were placed into $10 \%$ neutralized Formalin (phosphate buffer), and the other half into $95 \%$ ethanol.

Those animals placed into Formalin were razor sectioned and examined for internal malformations, while those in alcohol were used for skeletal examination.

\section{Teratological Procedure}

Razor section. Following at least 4 weeks of fixation in $10 \%$ neutralized Formalin, razor sections in the planes of the Wilson (1973) atlas were made and examined for malformations by eye or with the dissection scope if needed. No attempt at cellular histology was made.

Skeletal examination. Following at least 2 weeks of fixation in ethanol, the fetuses were cleared and the bones stained with Alizarin Red according to the method of Dawson (1926). The skeletons were examined under the dissection scope and anomalies noted.

\section{Results}

All but one female successfully mated. This animal was in the water group, and thus the data for this group were based on an $N$ of 5 instead of 6 . Since no apparent differences occurred between the three water subgroups, their data were pooled and used as the water control for all drug treatment conditions. The overall results of the mating are presented in Table 1. Only one animal (in the $4-\mathrm{g} / \mathrm{kg}$ condition)

Table 1

Pregnancy Outcome in Experiment 1

\begin{tabular}{cccccc}
\hline $\begin{array}{c}\text { Dose } \\
\text { Condition* }\end{array}$ & $\begin{array}{c}\text { Preg- } \\
\text { nancies }\end{array}$ & $\begin{array}{c}\text { Viable } \\
\text { Offspring }\end{array}$ & $\begin{array}{c}\text { Intra- } \\
\text { uterine } \\
\text { Deaths }\end{array}$ & $\begin{array}{c}\text { Resorp- } \\
\text { tions }\end{array}$ & $\begin{array}{c}\text { Corpus } \\
\text { Lutea }\end{array}$ \\
\hline $\mathrm{H}_{2} \mathrm{O}$ & $5 / 6$ & 55 & 0 & 3 & 59 \\
2 & $4 / 4$ & 45 & 0 & 2 & 49 \\
3 & $4 / 4$ & 51 & 0 & 5 & 57 \\
4 & $3 / 4$ & 34 & 1 & 0 & 35 \\
\hline
\end{tabular}

*Dose in grams of ethanol per kilogram body weight.

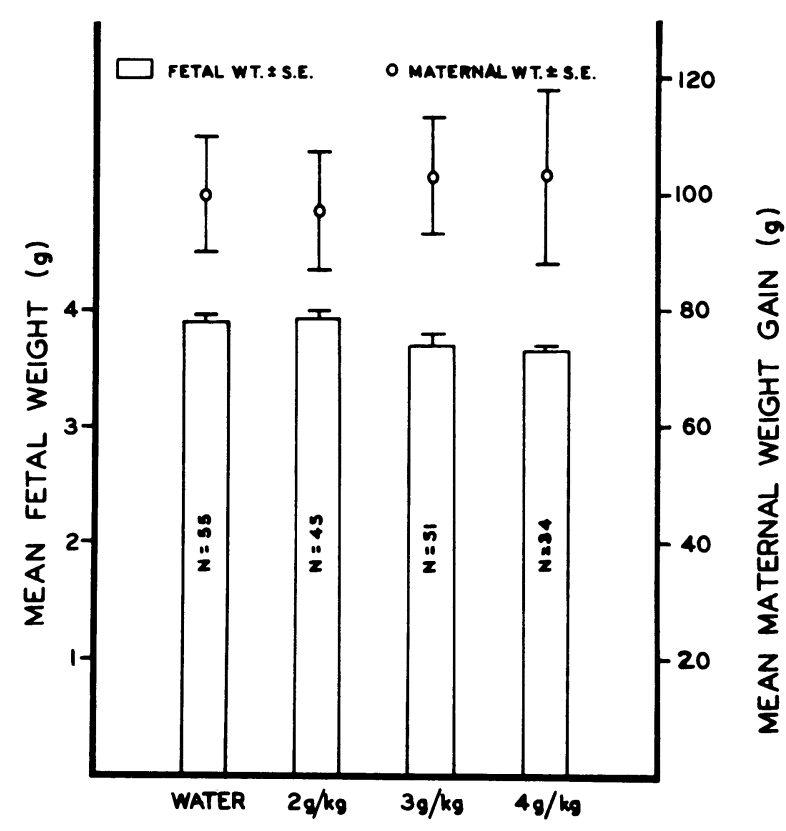

Figure 1. Fetal and maternal weight gains at Day 20 of gestation following either water or ethanol treatment on Days 9-12. (Dosage is in grams ethanol/kilogram body weight.)

had any major failure of ova implantation. This animal had only two viable fetuses with no visible resorptions for 10 corpus lutea found. Because of the disproportionately large size of these two fetuses, they were excluded from the data analysis. It could be that ethanol interfered with implantation, but this cannot be evaluated without further experimentation to increase the sample size. Excluding that animal, there were no significant differences between any of the treatment conditions on the mean number of viable young.

No gross fetal malformations were found for any condition. Only one nonviable fetus was found, and it occurred in the $4-\mathrm{g} / \mathrm{kg}$ condition. It was quite small (weight $=2.17 \mathrm{~g}$, length $=28 \mathrm{~mm}$ ), but showed no gross physical defects. The placenta for this stillborn animal, while below the mean (.34 g), was not out of the normal range.

No statistically significant differences between the final maternal weight gains during gestation were observed across conditions (see Figure 1). The mean cumulative weight gains are shown in Figure 2. During the treatment days, weight gains were suppressed in rats in both the $3-$ and $4-\mathrm{g} / \mathrm{kg}$ dose conditions. However, their weights rapidly caught up to those of the other conditions after the 4 treatment days, and all conditions were equal during the final 5 days of gestation.

A one-way analysis of variance performed on fetal weight revealed an overall significant difference for fetal weight $[F(3,183)=3.132, p<.05]$ (see Figure 1). Orthogonal comparisons of the weights of both the 3 - (mean weight $=3.65 \mathrm{~g} \pm .04)$ and $4-\mathrm{g} / \mathrm{kg}$ 


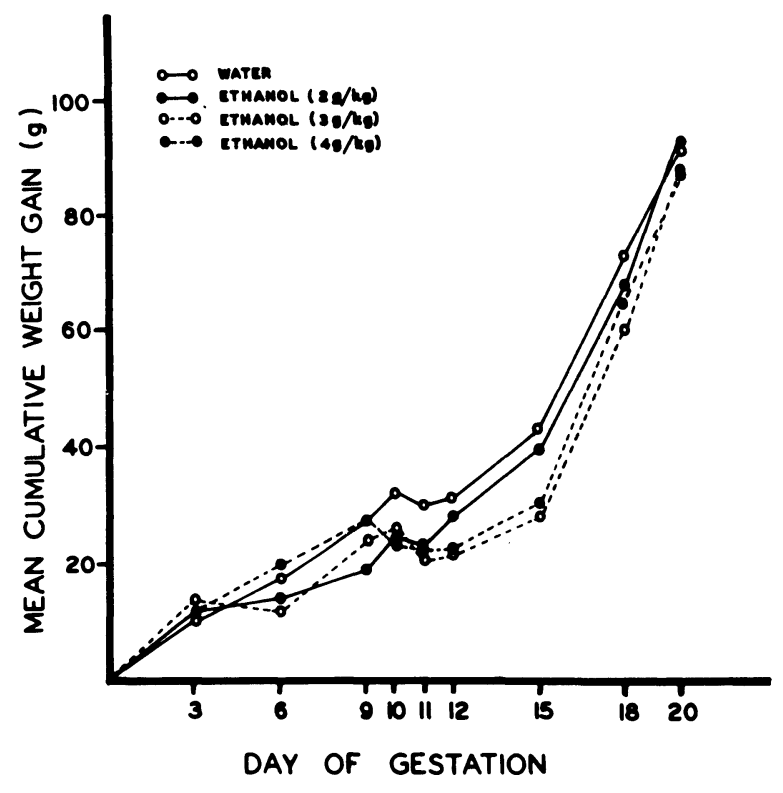

Figure 2. Cumulative maternal weight gain for all treatment conditions in Experiment 1 from Day 0 to Day 20 of gestation.

(mean weight $=3.61 \mathrm{~g} \pm .04$ ) conditions were found to be significantly lower than those of the water conditions [mean weight $=3.86 \mathrm{~g} \pm .03 ; \mathrm{t}(183)=2.361$, $\mathrm{p}<.01]$. No significant differences were found between the 3- and $4-\mathrm{g} / \mathrm{kg}$ groups. Similar analyses for fetal length and placental weight found no significant differences. This weight decrement at the 3- and $4-\mathrm{g} / \mathrm{kg}$ dose represents an approximate $6.5 \%$ growth deficiency, and is one standard deviation below the mean of the control group.

The razor sectioning found only two anomalies. In one animal in the $3-\mathrm{g} / \mathrm{kg}$ dose condition, there was agenesis of the left lung. In a pup from the water condition, the left kidney was missing. No other anomalies were observed.

The bone staining found a single pup from the $3-\mathrm{g} / \mathrm{kg}$ condition with the 12 th and 13 th ribs missing. No other defects were observed.

\section{Discussion}

The only significant finding was a small fetal weight decrement for those animals treated with either 3 or $4 \mathrm{~g} / \mathrm{kg}$ ethanol during the days of organogenesis. Unfortunately, it is these two conditions in which material weight gain shows a marked suppression during treatment, and even though the total weight gains by Day 20 are not different between the groups, this suppression of growth during the treatment could account for the observed weight differences. To examine this confound, the following experiment was performed.

\section{EXPERIMENT 2}

In order to determine the contributing factor of limited weight gain during the days of organogenesis and compare it to the effects of a high daily dose of ethanol during this period, the following experiment was conducted.

\section{Method}

\begin{abstract}
Animals
Fifteen adult female rats (Long-Evans strain), weighing between 245 and $345 \mathrm{~g}$, were maintained as in Experiment 1.

\section{Procedure}

The animals were impregnated as in Experiment 1 and were then placed in one of two groups. One group received $4 \mathrm{~g}$ ethanol/kg body weight intragastrically on Days $9,10,11$, and 12 of gestation. The other group received an intragastric water load of equal volume on those days. The water group was also food restricted during drug administration days, such that their body weights remained comparable to the ethanol group. All other procedures were repeated exactly as in Experiment 1, except that the autopsies were performed at $1500 \mathrm{~h}$ instead of $0900 \mathrm{~h}$ on Day 20. Furthermore, on Days 9 and 12, tail blood samples from some animals were taken $1 \mathrm{~h}$ after drug administration for determination of blood ethanol levels using the enzymatic method (Brink et al., 1954).
\end{abstract}

\section{Results}

All animals were successfully mated. The overall results are presented in Table 2 . No differences between conditions were found.

Figure 3 presents the cumulative mean weight gains for the animals during gestation. No reliable differences occurred for any data point, but as can be seen during the treatment phase (i.e., Days 9, 10, 11 , and 12), the water animals actually had lower mean accumulated body weight than animals in the ethanol group.

The mean blood ethanol levels on Day $9(1 \mathrm{~h}$ after administration) were $203.9 \mathrm{mg}$ ethanol $/ 100 \mathrm{ml}$ blood ( \pm 26.6$)$ and on Day 12 were $167.6 \mathrm{mg}$ ethanol/ $100 \mathrm{ml}( \pm 21.1)$. The levels across the two samples were not significantly different, but the trend for lower blood levels on Day 12 supported the concurrent decreased behavioral impairment that was observed to exist in all animals. However, the blood levels were still high enough to produce ataxic and righting difficulties on Day 12.

Examination of the fetuses on Day 20 revealed a single malformation in one animal from the $4-\mathrm{g} / \mathrm{kg}$ group (exencephaly). The only significant difference found was for the body weight measure (see Figure 4). The water animals had a mean body weight of $4.26 \pm .05 \mathrm{~g}$, while the alcohol animals

Table 2

Pregnancy Outcome in Experiment 2

\begin{tabular}{|c|c|c|c|c|c|}
\hline $\begin{array}{c}\begin{array}{c}\text { Dose } \\
\text { Condition* }\end{array} \\
\end{array}$ & $\begin{array}{c}\text { Preg- } \\
\text { nancies }\end{array}$ & $\begin{array}{c}\text { Viable } \\
\text { Offspring }\end{array}$ & $\begin{array}{l}\text { Intra- } \\
\text { uterine } \\
\text { Deaths }\end{array}$ & $\begin{array}{l}\text { Resorp- } \\
\text { tions }\end{array}$ & $\begin{array}{c}\text { Corpus } \\
\text { Lutea }\end{array}$ \\
\hline $\begin{array}{l}\mathrm{H}_{2} \mathrm{O} \\
4\end{array}$ & $\begin{array}{c}5 / 5 \\
10 / 10\end{array}$ & $\begin{array}{r}63 \\
111\end{array}$ & $\begin{array}{l}0 \\
0\end{array}$ & $\begin{array}{l}5 \\
7\end{array}$ & $\begin{array}{r}68 \\
121\end{array}$ \\
\hline
\end{tabular}

*Dose in grams of ethanol per kilogram body weight. 


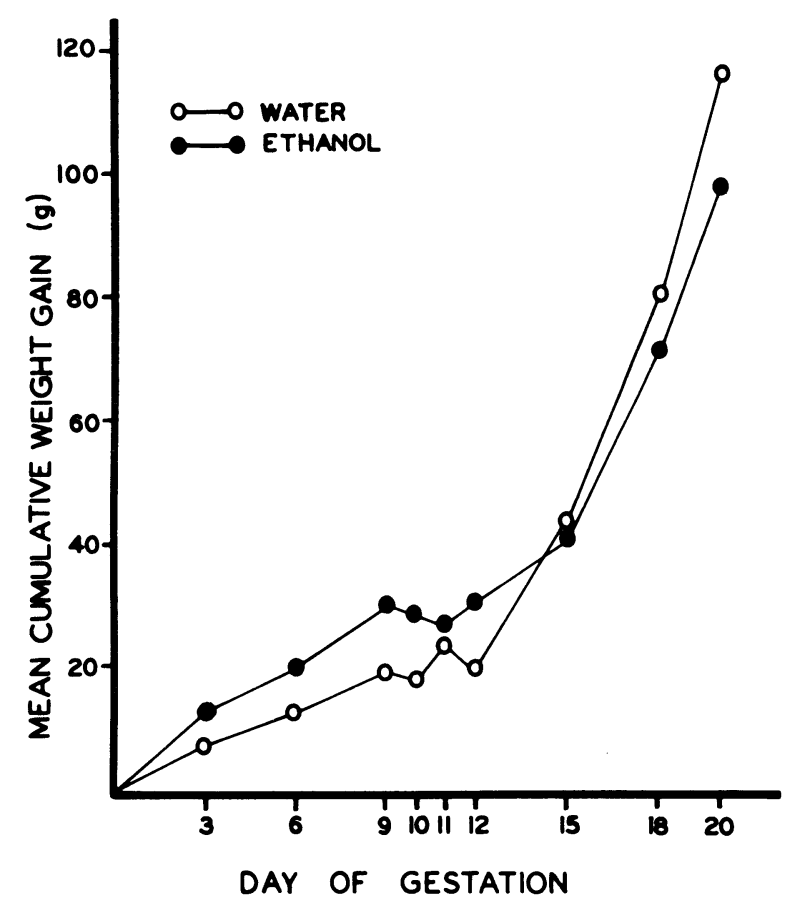

Figure 3. Cumulative maternal weight gain for both treatment conditions in Experiment 2 from Day 0 to Day 20 of gestation.

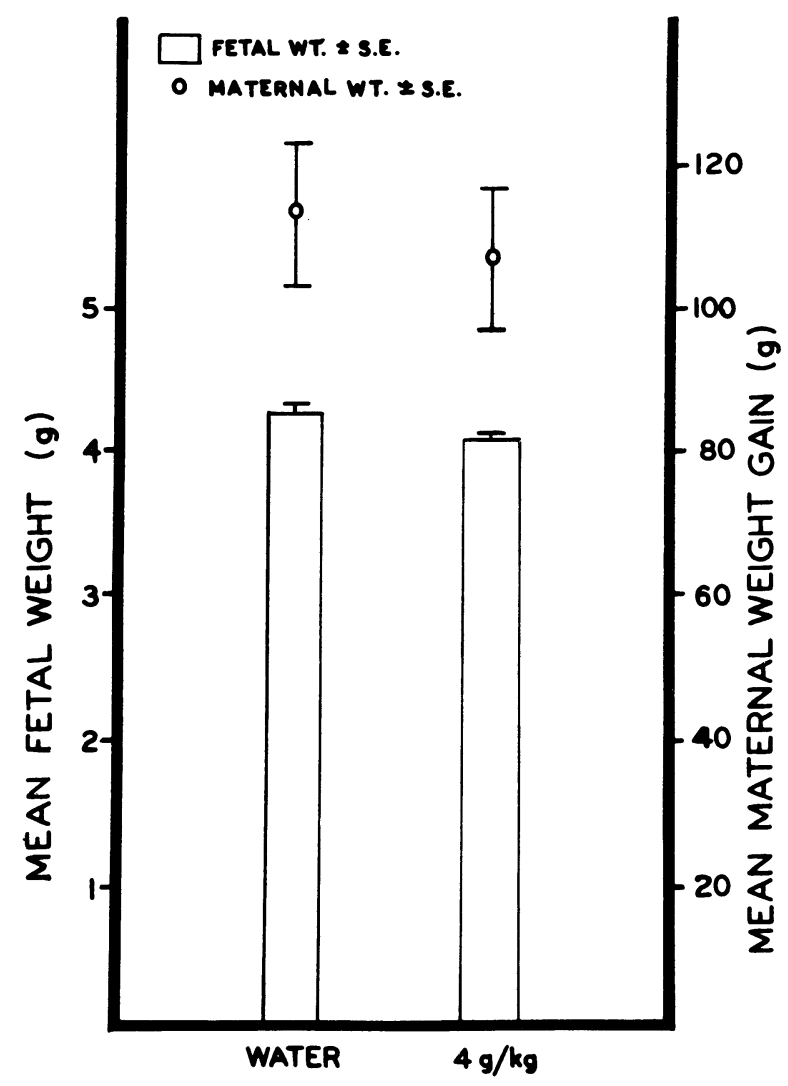

Figure 4. Fetal and maternal weight gains at Day 20 of gestation following either water or ethanol treatment on Days 9-12. (Dosage is in grams ethanol/kilogram body weight.) weighed $4.08 \pm .04 \mathrm{~g}$. An analysis of variance was significant, with $\mathrm{p}<.01[\mathrm{~F}(1,141)=7.049]$. This is a $4.3 \%$ reduction in mean body weight. The razor sections found one animal in the ethanol group that was hydronephretic on the left side. Among the animals cleared and bone stained, one animal in the ethanol group was found in which the 8th and 9th ribs on the rights side were missing. No other anomalies were observed.

\section{GENERAL DISCUSSION}

The results indicate that, while the effect is small, there is a significant reduction of body weight due to acute ethanol exposure during organogenesis. This reduction cannot be accounted for by decreased maternal weight gain during treatment, as water control animals that actually gained less weight than treated animals during the treatment days had offspring of normal weight (i.e., when compared to nontreated control animals). While the fetal body weights in Experiment 1 were all lighter than those of Experiment 2, this difference can be accounted for by the earlier time of day of the autopsy in Experiment 1 .

The finding that a dose of $2 \mathrm{~g}$ ethanol $/ \mathrm{kg}$ had very minor, nonsignificant fetal effects corroborates the data of Abel (1978), who found no effect upon fetal development of $1 \mathrm{~g}$ ethanol $/ \mathrm{kg}$ given throughout gestation. Skosyreva (1973) reported that $1.6 \mathrm{~g}$ ethanol/ $\mathrm{kg}$ administered on Days 8-14 of gestation resulted in smaller fetuses at Day 21 (ethanol group $=3 \mathrm{~g}$, controls $=3.8 \mathrm{~g}$ ). This is a much larger effect than was found in these experiments, even at the $4-\mathrm{g} / \mathrm{kg}$ dose. It is possible that the difference between these studies is due to the strain of rat used. However, the use of $40 \%$ ethanol as the concentration for gavage could produce effects much different from the $15 \%$ used in the present studies. No blood ethanol levels or maternal weight gains are reported in the Skosyreva study, making comparison impossible. One other factor possible for the differences could be the added 3 days of ethanol treatment used by Skosyreva, but if compared to the Abel data, which administered $1 \mathrm{~g} / \mathrm{kg}$ throughout gestation, this is not a compelling argument for the differences seen.

While making a direct assumption as to the effects of acute ethanol exposure during pregnancy in the human is difficult, the data suggest that moderate to heavy (i.e., a binge) drinking occurring during organogenesis could, even with proper nutrition, result in growth retardation. What possible mental retardation might concurrently result from this growth retardation remains to be determined.

\section{REFERENCES}

Abel, E. L. Effects of ethanol on pregnant rats and their offspring. Psychopharmacology, 1978, 57, 5-11. 
Brink, N. G., Bonnichisen, R., \& Theorell, H. A modified method for the enzymatic micro-determination of ethanol. Acta Pharmacologica et Toxicologica, 1954, 10, 223-226.

Chernoff, G. F. The fetal alcohol syndrome in mice: An animal model. Teratology, 1977, 15, 223-230.

Dawson, A. B. A note on the staining of cleared specimens with Alizarin Red S. Stain Techniques, 1926, 1, 123-124.

Hanson, J. W., Jones, K. L., \& Smith, D. W. Fetal alcohol syndrome: Experience with 41 patients. Journal of the American Medical Association, 1976, 235, 1458-1460.

Henderson, G., I., \& Schenker, S. The effect of maternal alcohol consumption on the viability and visceral development of the newborn rat. Research Communications in Chemical Pathology and Pharmacology, 1977, 16, 15-32.

Jones, K. L. \& Smith, D. W. Recognition of the fetal alcohol syndrome in early infancy. Lancet, 1973, 2, 999-1001.

Jones, K. L., Smith, D. W., Ulle land, C. N., \& Streissguth, A. P. Pattern of malformation in offspring of chronic alcoholic mothers. Lancet, 1973, 2, 1267-1271.
Jones, K. L., Smith, D. W., \& Hanson, J. W. The fetal alcohol syndrome: Clinical delineation. Annals of the New York Academy of Science, 1976, 273, 130-137.

Mulvihill, J. J., \& Yeager, A. M. Fetal alcohol syndrome. Teratology, 1976, 13, 345-348.

RAnDall, C. R. Teratogenic effects of the in utero ethanol exposure. In K. Blum (Ed.), Alcohol and opiates. New York: Academic Press, 1977.

Skosyreva, A. M. Effects of ethyl alcohol on the development of embryos at the organogenesis stage. Akush Ginek Mosk, 1973, 4, 15-18 (CAAAL \#360029).

Wilson, J. G. Environment and birth defects. New York: Academic Press, 1973.

(Received for publication April 20, 1979; revision accepted July 13, 1979.) 